\title{
Antiradical, Anti-inflammatory and Antifungal Activities of Essential Oils of Two Aromatic Plants: Apium graveolens (Apiaceae) and Thymus vulgaris (Lamiaceae)
}

\author{
Marguerite Simo Kamdem¹, Modeste Lambert Sameza ${ }^{2}$, Pierre Michel Jazet Dongmo ${ }^{2}$, Fabrice Fekam Boyom , \\ Issakou Bakargna-Via ${ }^{1}$, Jean Baptiste Hzounda Fokou ${ }^{1}$, Ide Flavie Kenfack Tsague ${ }^{1}$, Elisabeth Zeuko'o Menkem ${ }^{1}$, \\ Paul Henri Amvam Zollo ${ }^{3}$ and Chantal Menut ${ }^{4}$ \\ 1. Department of Biochemistry, Faculty of Science, University of Yaoundé I, Yaoundé, P.O Box 812, Cameroon \\ 2. Department of Biochemistry, Faculty of Science, University of Douala, Douala, P.O Box 24157, Cameroon \\ 3. ENSAI, University of Ngaoundere, Ngaoundere, P.O Box 455, Cameroon \\ 4. IBMM, Montpellier-UMR 5247, Faculté de Pharmacie, 15 Avenue Charles Flahault, Montpellier 34093, France
}

Received: April 18, 2014 / Accepted: January 23, 2015 / Published: February 28, 2015.

\begin{abstract}
The outbreak of oxidative stress, inflammatory diseases and mycoses, constitute an important public health problem. This could be due to the increase of risk factors, side effects and expensive therapeutic molecules available. In the aim to find the potential spring of new therapeutic molecules with efficient and wide spectrum of action, the antiradical, anti-inflammatory and antifungal activities of two essential oils were evaluated. The essential oils were extracted by hydrodistillation. The antiradical activity was evaluated to use DPPH (2,2-diphenyl-1-picrylhydrazyl) scavenging method and the anti-inflammatory activity was determined using the enzymatic method. The disc diffusion and dilution methods were used to evaluate growth inhibition of three yeasts, three moulds and three dermatophytes. The yields of extraction of Apium graveolens and Thymus vulgaris essential oils were $0.14 \%$ and $0.32 \%$ respectively. These essential oils showed antiradical properties with respective $\mathrm{SC}_{50}$ of 0.41 and $0.06 \mathrm{~g} / \mathrm{L}$ for Apium graveolens and Thymus vulgaris. Only Thymus vulgaris presented an anti-inflammatory activity with an $\mathrm{IC}_{50}$ of $0.19 \mathrm{~g} / \mathrm{L}$. Cryptococcus neoformans was the most susceptible fungal strain while C. albicans was the most resistant one. The results were compared with the standard antifungal. These results show that these essential oils could be exploited as potential spring of molecules endowed with antiradical, anti-inflammatory and antifungal activities.
\end{abstract}

Key words: Essential oil, antiradical, anti-inflammatory, antifungal.

\section{Introduction}

The dysfunctions of oxygen metabolism generate an excess of reactive chemical species known as ROS (reactive oxygen species), and among them are free radicals (like $\mathrm{OH}, \mathrm{O}_{2} \cdot \mathrm{RO}_{2}$ ), and non-radical products (like $\mathrm{H}_{2} \mathrm{O}_{2}, \mathrm{RO}_{2} \mathrm{H}$ ). These species, particularly the radical species, create oxidative damages on biological macromolecules (DNA, lipids and proteins) which can considerably disturb the cell machinery [1].

Corresponding author: Pierre Michel Jazet Dongmo, Ph.D., research field: biochemistry and natural products. E-mail: mjazet@yahoo.com.
Chronic stress and malnutrition represents $90 \%$ of the causes of immunodepression in subjects without basal pathologies, and are key to the entry into the epithelial and endothelial tissues of fungal species coexisting in the environment [2]. Oxidative stress is involved in numerous pathologies (atherosclerosis, diabetes, neurodegenerative diseases, cancer...) and in the aging process [1]. In order to prevent this, synthetic antioxidants such as BHA (butyl hydroxyanisole) and BHT (butyl hydroxytoluene) are used to stabilize these products for a long time. Due to the known detrimental effects of BHA and BHT, there has been a 

Apium graveolens (Apiaceae) andThymus vulgaris (Lamiaceae)

remarkable growth in the demand for natural antioxidants within the past few years. Recently, researchers have focused on natural antioxidants such as essential oils which are used for many purposes including flavoring foods and beverages, aroma additives for cosmetics and household products, and masking agents for unpleasant odors. These essential oils are extracted from aromatic plants which are widely used in traditional medicine to treat many diseases. For example, Thymus vulgaris plant is used in traditional medicine of Cameroon against respiratory infections (asthma, cough, whooping cough, bronchitis), rheumatism and the tea are consumed as stimulant by elderly person [3]. Previous reports showed various biological actions of essential oils such as antifungal, antibacterial, antimicrobial, hypolipidemic, antioxidant and anti-inflammatory properties [4-7]. The study aimed to evaluate the antiradical, anti-inflammatory and antifungal potentials of essential oils of leaves of $A$. graveolens and T. vulgaris (leaves and stem).

\section{Materials and Methods}

\subsection{Plant Material and Extraction Procedure}

The fresh leaves of $A$. graveolens (Celery) and $T$. vulgaris (thyme) were collected in Yaoundé and Dschang in August 2012 respectively. They were identified at the Cameroon National Herbarium in Yaounde with identification numbers 25582/SRF-Cam and 42851-Cam respectively where voucher specimens were deposited. The essential oils tested were extracted by the hydrodistillation method using Clevenger-type apparatus. The recovered oils were dried over anhydrous sodium sulphate and stored at $4{ }^{\circ} \mathrm{C}$.

\subsection{Fungal Strains}

The fungal strains used in the study were obtained from the "Centre Pasteur" of Yaounde, Cameroon. These strains were three yeasts (Candida albicans ATCC24433, Candida glabrata CIPA35,
Cryptococcus neoformans IP 95026), three moulds (Aspergillus flavus, Aspergillus fumigatus and Aspergillus niger) and three dermatophytes (Epidermophyton floccosum E1423, Microsporum gypseum E1420, Trichophyton mentagrophytes E1425).

\subsection{Analysis of Essential Oils}

The essential oils obtained were analysed by GC (gas chromatography) and GC/MS (gas chromatography coupled with mass spectrometry).

\subsubsection{Gas Chromatography}

The oils were analysed on a Varian CP-3380 GC with flame ionization detector fitted with a fused silica capillary column $(30 \mathrm{~m} \times 0.25 \mathrm{~mm}$ coated with DB5, film thickness $0.25 \mu \mathrm{m})$; temperature program $50-200{ }^{\circ} \mathrm{C}$ at $5{ }^{\circ} \mathrm{C} / \mathrm{min}$, injector temperature $200{ }^{\circ} \mathrm{C}$, detector temperature $200{ }^{\circ} \mathrm{C}$, carrier gas nitrogen $\left(\mathrm{N}_{2}\right)$, $1 \mathrm{~mL} / \mathrm{min}$. The linear retention indices of the components were determined to use the retention times of a series of n-alkanes and the percentage compositions were obtained from electronic integration measurements without taking relative response factors into account.

2.3.2 Gas Chromatography Coupled with Mass Spectrometry

GC/MS analyses were performed using a Hewlett-Packard apparatus equipped with an HP1 fused silica column $(30 \mathrm{~m} \times 0.25 \mathrm{~mm}$, film thickness $0.25 \mu \mathrm{m})$ and interfaced with a quadrupole detector (GC-quadrupole MS system, model 5970). The column temperature was programmed from $70-200{ }^{\circ} \mathrm{C}$ at $10{ }^{\circ} \mathrm{C} / \mathrm{min}$; injector temperature was $200{ }^{\circ} \mathrm{C}$. Helium was used as the carrier gas at a flow rate of $0.6 \mathrm{~mL} / \mathrm{min}$; the mass spectrometer was operated at $70 \mathrm{eV}$.

The constituents were identified on the basis of the comparison of their retention indices and mass spectra with those given in the literature [8].

\subsection{Determination of Antiradical Activity}

The antiradical activity of the essential oil was 
determined using scavenging 2, DPPH (2-diphenyl-1-picrylhydrazyl) method according to Brand-Williams et al. [9], and Cuvelier et al. [10]. This stable free radical scavenger was dissolved in ethanol for a stock solution $(0.4 \mathrm{~g} / \mathrm{L})$ then a serial dilution was realized. The ethanolic solution of DPPH $(1900 \mu \mathrm{L})$ was mixed with the methanolic solution of BHT $(100 \mu \mathrm{L})$ at different concentrations. The essential oil was tested using the same method. The control was made of the DPPH ethanolic solution with methanol. The absorbance was measured at $517 \mathrm{~nm}$ during $1 \mathrm{~h}$, at room temperature. The decrease in absorption induced by the test compound was calculated by substracting that of the control. The concentration required for $50 \%$ reduction $(50 \%$ scavenging concentration, SC50) was determined graphically. All the spectrophotometric measurements were performed using a SAFAS UV-mc2 Spectrophotometer, equipped with a multi-cells/ multikinetic measure system and with a thermostated cell-case.

\subsection{Determination of Anti-inflammatory Activity}

The anti-inflammatory activity was determined to using the enzymatic method; inhibition of 5-Lipoxynase according to Safayhi et al. [11], and Braga et al. [12]. Lipoxygenase is known to catalyse the oxidation of unsaturated fatty acids containing 1-4 diene structures. The conversion of linoleic acid was followed spectrophotometrically by the appearance of a conjugate diene at $234 \mathrm{~nm}$. NDGA (Nordihydroguiaretic acid), a known inhibitor of soybean lipoxygenase, was used as a reference drug. The reaction was initiated by the addition of aliquots $(50 \mu \mathrm{L})$ of a Soybean lipoxygenase solution (prepared daily in potassium phosphate buffer $0.1 \mathrm{M} \mathrm{pH} 9$ in a sufficient concentration to give an easily measurable initial rate of reaction) to $2.0 \mathrm{~mL}$ of sodium linoleate $100 \mu \mathrm{M}$ in phosphate buffer; the enzymatic reactions were performed in the absence or the presence of the inhibitor and their kinetics were compared. The inhibitors were dissolved in ethanol such that an aliquot of each $(10 \mu \mathrm{L})$ yielded a final concentration of maximum $300 \mathrm{ppm}$ in each assay The initial reaction rate was determined from the slope of the straight line portion of the curve and the percentage inhibition of the enzyme activity was calculated by comparing with the control (using $10 \mu \mathrm{L}$ of ethanol instead of $10 \mu \mathrm{L}$ of the inhibitor-ethanol solution). Each inhibitor concentration was tested in triplicate and the results averaged; the concentration that gave $50 \%$ inhibition $\left(\mathrm{IC}_{50}\right)$ was calculated from the outline of the inhibition percentages as a function of the inhibitor concentration.

\subsection{Determination of Antifungal Activities}

\subsubsection{Disc Diffusion Method}

The disc diffusion method was used for the antifungal screening as described by Rubio et al. [13]. The SDA (Sabouraud dextrose agar) medium prepared according to the manufacturer' guides and $10 \mathrm{~mL}$ poured into Petri dishes of $55 \mathrm{~mm}$ and allowed to rest for solidification. The essential oils were dissolved in $10 \%$ DMSO (dimethylsulfoxyde) at different proportion $(\mathrm{v} / \mathrm{v})$. The yeast suspensions at $2.5 \times 10^{5}$ $\mathrm{CFU} / \mathrm{mL}$ were prepared from $48 \mathrm{~h}$ old cultures in a saline solution. After the solidification, each Petri dish was seeded with yeast suspension, then sterile paper discs ( $4.0 \mathrm{~mm}$ in diameter) impregnated with $15 \mu \mathrm{L}$ of essential oils/DMSO were placed at the centre of each dish, and Nystatin was used as positive control. Negative controls were prepared in the same conditions except essential oils. The dishes were incubated in an inverted position at $37{ }^{\circ} \mathrm{C}$ for $48 \mathrm{~h}$. The diameters of the inhibition zones were measured in $\mathrm{mm}$ for 3 days. All the tests were performed in triplicate.

\subsubsection{Minimal Inhibitory Concentration}

The MIC (minimal inhibitory concentration) which inhibits the visible growth of fungi was determined by the micro-well dilution method of Tchoumbougnang [14] using SNB (Sabouraud Nutrient Broth). The 
essential oils were dissolved in 10\% DMSO for $A$. graveolens $(80 \% \mathrm{v} / \mathrm{v})$ and $T$. vulgaris $(20 \% \mathrm{v} / \mathrm{v})$. In the 96-wellplates, $100 \mu \mathrm{L}$ of SNB were dispensed into each well except first well which had 150 or $180 \mu \mathrm{L}$ of SNB following each essential oil. A volume of the stock solution of essential oils was added into the first well to give $200 \mu \mathrm{L}$ as final volume. Then two-fold serial dilutions was done and $20 \mu \mathrm{L}$ of the inocula were introduced into each well. The final volume in each well was $120 \mu \mathrm{L}$. The negative control contained SNB and inoculum. The essential oil concentrations of A. graveolens and T. vulgaris ranged from 140-0.14 $\mathrm{g} / \mathrm{L}$ and 56.67-0.06 $\mathrm{g} / \mathrm{L}$ respectively. Nystatin was used as a positive control with concentration of $2.77-0.0027 \mathrm{~g} / \mathrm{L}$. The microplates were covered with a sterile plate sealer and then incubated for $48 \mathrm{~h}$ at $37^{\circ} \mathrm{C}$.

\subsubsection{Minimal Fungicidal Concentration}

For confirmation of the fungistatic or fungicidal activity, all wells showing no visible growth after $48 \mathrm{~h}$ were subcultured on to SDA medium and incubated at $37{ }^{\circ} \mathrm{C}$ for $48 \mathrm{~h}$. The MFC was recorded as the lowest concentration that did not yield growth.

2.6.4 Anti-Moulds and Anti-Dermatophytes Assays

The preliminary screening and determination of MIC (minimal inhibitory concentration) were done by agar dilution method described by Grover and Moore [15], and De Billerbeck [16], and essential oil was dissolved in DMSO in a proportion of $1 / 9$. The essential oil solution was mixed in the SDA medium with concentrations of $1.275 \mathrm{~g} / \mathrm{L}, 2.550 \mathrm{~g} / \mathrm{L}$, and 5.100 $\mathrm{g} / \mathrm{L}$ for A. graveolens and $0.255 \mathrm{~g} / \mathrm{L} ; 0.510 \mathrm{~g} / \mathrm{L} ; 0.765$ $\mathrm{g} / \mathrm{L}$ (moulds) $0.085 \mathrm{~g} / \mathrm{L} ; 0.255 \mathrm{~g} / \mathrm{L} ; 0.510 \mathrm{~g} / \mathrm{L}$ (dermatophyytes) for T. vulgaris. The Amphotericin B and Griseofulvin were used as positive controls and negative control was only SDA medium in the dish with inoculum. The $10 \mathrm{~mL}$ of the supplemented SDA medium was poured into Petri dishes of $55 \mathrm{~mm}$ per dish and allowed to rest for solidification. A mycelia disc of $6 \mathrm{~mm}$ in diameter of 4 and 7 days old preculture of Aspergillus and dermatophytes respectively was inoculated at the center of the dish. The dishes were incubated in an inverted position at $37^{\circ} \mathrm{C}$ in the dark during 7 and 15 days for moulds and dermatophytes respectively. The mycelia growth was observed while measuring the diameter according to two perpendicular lines passing across the centre of the dish. For each concentration, three tests were carried out.

\subsubsection{Statistical Analysis}

Data from three independent replicate trials were subjected to statistical analysis using ANNOVA by Student-Fisher $p<0.05$ Add software.

\section{Results and Discussion}

\subsection{Yields of Extraction of Essential Oils}

The hydrodistillation of the leaves of $A$. graveolens and T. vulgaris gave the yield of $0.14 \pm 0.04 \%$ and $0.32 \pm 0.04 \%$ respectively. These results were different to those previously obtained by Nguefack et al. [17] who showed a yield of $0.50 \%$ for dry $T$. vulgaris from Dschang region of Cameroon. These variations could be explained by the post-harvest treatment.

\subsection{Chemical Composition}

The results of the chemical analysis are presented in Table 2.

The essential oils of $A$. graveolens and $T$. vulgaris were made of monoterpenoids $(79.9 \%$ and $89.8 \%$ respectively) with limonene $(50.7 \%)$ and myrcene (12.5\%) in that of A. graveolens and thymol (57.9\%)

Table 1 Yield of extraction.

\begin{tabular}{lll}
\hline Essential oils & A. graveolens & T. vulgaris \\
\hline Yield & $0.14 \pm 0.04 \%$ & $0.32 \pm 0.02 \%$ \\
Color & yellow (light) & yellow \\
\hline
\end{tabular}


Antiradical, Anti-inflammatory and Antifungal Activities of Essential Oils of Two Aromatic Plants: Apium graveolens (Apiaceae) andThymus vulgaris (Lamiaceae)

Table 2 Chemical composition of $A$. graveolens and $T$. vulgaris essential oils.

\begin{tabular}{|c|c|c|c|}
\hline IK & Compounds & $\begin{array}{l}\text { Percentage }(\%) \\
\text { A. graveolens }\end{array}$ & T. vulgaris \\
\hline & Monoterpenes & 79.9 & 89.8 \\
\hline & Hydrogenatedmonoterpens & 65.7 & 11.4 \\
\hline 935 & $\alpha$-pinene & 0.2 & - \\
\hline 971 & sabinene & 0.3 & - \\
\hline 978 & ß-pinene & 0.2 & - \\
\hline 987 & myrcene & 12.5 & 0.4 \\
\hline 1019 & p-cymene & 1.4 & 10.3 \\
\hline 1035 & limonene & 50.7 & 0.5 \\
\hline 1041 & (E)-B-ocimene & 0.2 & - \\
\hline 1056 & $\alpha$-terpinene & - & 0.2 \\
\hline \multirow[t]{2}{*}{1196} & ð-terpinene & 0.2 & - \\
\hline & Oxygenatedmonoterpens & 14.2 & 78.4 \\
\hline 1055 & trans sabinene hydrate & - & 2.1 \\
\hline 1080 & fenchone & 0.5 & - \\
\hline 1094 & linalol & 0.1 & 6.9 \\
\hline 1135 & camphor & - & 2.3 \\
\hline 1139 & camphor 2 & - & 1.4 \\
\hline 1176 & terpinen-4-ol & 0.2 & 2.6 \\
\hline 1196 & ð-terpineol & 0.1 & 0.3 \\
\hline 1222 & nerol & - & 1.6 \\
\hline 1224 & thymol methylether & - & 0.9 \\
\hline 1233 & neral & - & 0.4 \\
\hline 1240 & geraniol & 0.3 & - \\
\hline 1248 & ð-carvyl acétate & 0.7 & - \\
\hline 1279 & neryl formate & - & 0.4 \\
\hline 1289 & thymol & 11.8 & 57.9 \\
\hline \multirow[t]{3}{*}{1352} & carvacrol & 0.5 & 1.6 \\
\hline & Sesquiterpens & 12.1 & 5.3 \\
\hline & Hydrogenatedsesquiterpens & 7.9 & 3.1 \\
\hline 1437 & ß-caryophyllene & 4.2 & 2.4 \\
\hline 1469 & $\alpha$-humulene & 0.3 & - \\
\hline 1481 & $\gamma$-himachalene & 0.1 & - \\
\hline 1499 & germacrene D & - & 0.3 \\
\hline 1502 & ß-bisabolene & 2.0 & - \\
\hline 1509 & $\beta$-selinene & 1.3 & - \\
\hline 1508 & valencene & - & 0.2 \\
\hline \multirow[t]{2}{*}{1522} & $\delta$-cadinene & - & 0.2 \\
\hline & Oxygenatedsesquiterpens & 4.2 & 2.2 \\
\hline 1529 & elemol & - & 0.5 \\
\hline 1595 & caryophyllene oxide & 0.4 & 1.7 \\
\hline 1627 & humulene oxide & 0.2 & - \\
\hline 1640 & caryophyllen-dienol & 0.5 & - \\
\hline 1717 & $2 \mathrm{E}, 6 \mathrm{Z}$ farnesol & 2.3 & - \\
\hline \multirow[t]{2}{*}{1814} & Farnesyl acetate & 0.8 & - \\
\hline & Aromatic compound & 0.4 & 3.7 \\
\hline 1156 & estragol & 0.4 & - \\
\hline \multirow[t]{2}{*}{1348} & eugenol & - & 3.7 \\
\hline & Aliphatic compounds & 0.8 & \\
\hline 1666 & heptadecene & 0.3 & - \\
\hline 1738 & tetradecenol & 0.5 & - \\
\hline
\end{tabular}


and p-cymene (10.3\%) for T. vulgaris. These results were similar to those obtained by Alfreda and Taka [18], with limonène (74.6\%) as major compound of the seeds of $A$. graveolens oil. These results were also similar to those obtained by Tchoumbougnang [14], with thymol $(27.2 ; 43.6 \%)$ and p-cymene (20.4; $34.8 \%$ ) as major compounds in the essential oil of $T$. vulgaris harvested from Bafoussam west region of Cameroon. It was also similar to those of Nguefack et al. [17] who showed thymol (27.2\%) and P-cymene (23.6\%) as major components of essential oils of $T$. vulgaris from Dschang area of Cameroon.

\subsection{Antiradical Activities of Essential Oils}

The antiradical properties of essential oils are illustrated in Figs 1-3 from which it can be seen that the percentage of free radical capture increased with the concentration of various essential oils in the reaction medium, up to a stationary state. From this, the $\mathrm{SC}_{50}$ of the samples were obtained (Table 3). The essential oil of $T$. vulgaris $\left(\mathrm{SC}_{50}=0.06 \pm 0.01 \mathrm{~g} / \mathrm{L}\right)$ was more effective than that of $A$. graveolens $\left(\mathrm{SC}_{50}=\right.$ $0.41 \pm 0.01 \mathrm{~g} / \mathrm{L}$ ). In addition, the antiradical activities of the studied extracts are significantly lower than those of BHT $\left(\mathrm{SC}_{50}=0.0071 \pm 0.000 \mathrm{~g} / \mathrm{L}\right)$. Indeed, these results are comparable to those of Alfreda and Taka [18] who showed that essential oils of $A$. graveolens have a low antiradical activity because at $0.20 \mathrm{~g} / \mathrm{L}$ it showed only $55 \%$ of scavenging of DPPH radicals. This results were also similar to those of Alitonou [19] where the essential oils were rich in monoterpenes hydrocarbons and/or sesquiterpenes and showed a weak antioxidant activity, but different to those of Yakhlef [20], with $\mathrm{SC}_{50}=88.00 \pm 2.876$ $\mu \mathrm{g} / \mathrm{mL}$ from apolar extract of $T$. vulgaris.

Antiradical activities showed by essential oils of these plants would be due to the presence of phenolics compounds like thymol and cavacrol as demonstrated by Sokmen et al. [21] who correlated the high antioxidant activity of essential oil of Thymus spathulifolius with their high quantities of thymol (36.5\%) and carvacrol (29.8\%).

\subsection{Anti-Infammatory Properties of Essential Oils}

The anti-infammatory property of $T$. vulgaris essential oil with that of nordihydroguaretic acid is presented in Figs. 4 and 5.

These figures help to determine the values of $\mathrm{IC}_{50}$ of the samples.

The extract sample of $A$. graveolens is not active

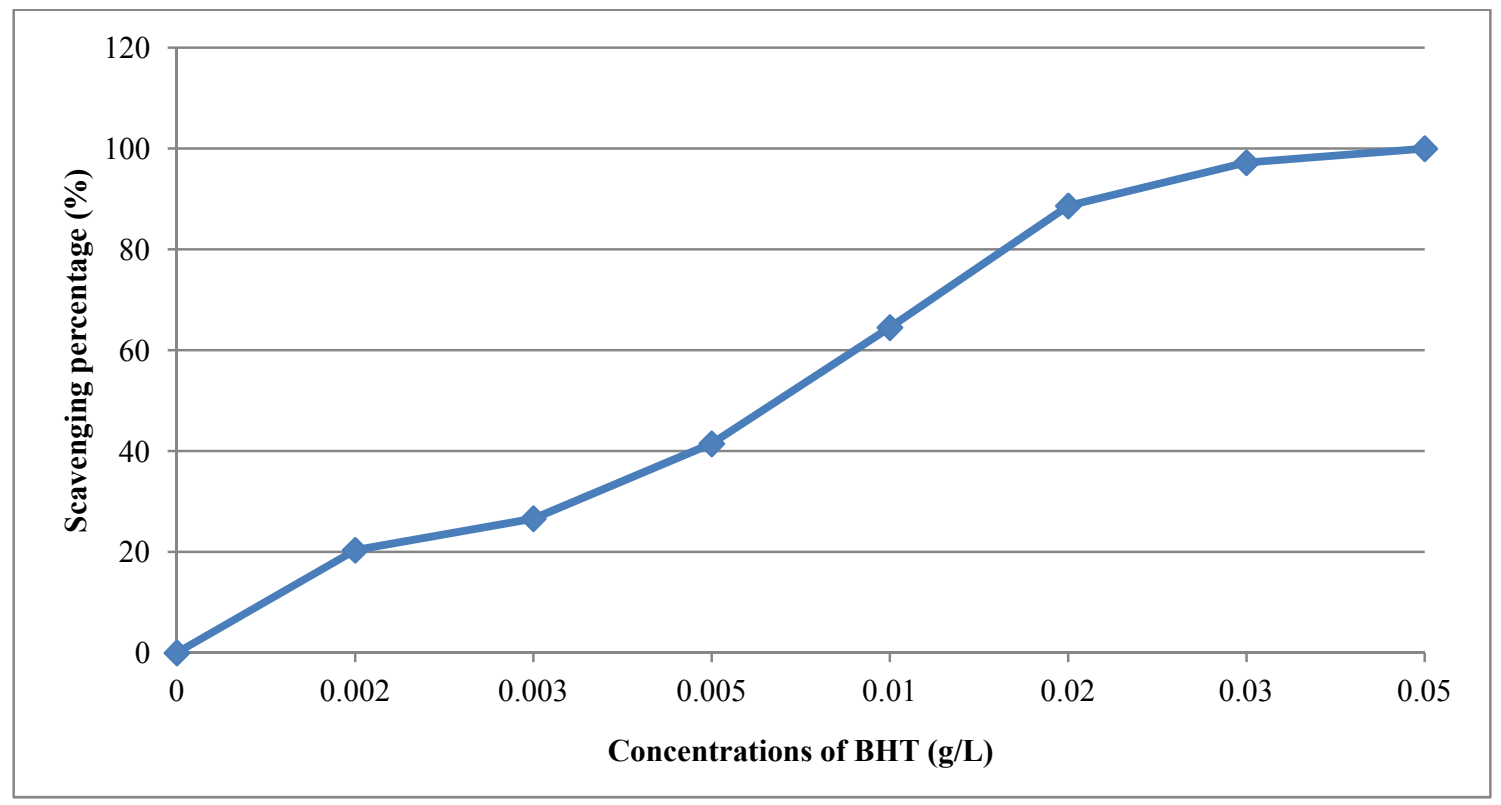

Fig. 1 Antiradical activity of BHT. 
Antiradical, Anti-inflammatory and Antifungal Activities of Essential Oils of Two Aromatic Plants: Apium graveolens (Apiaceae) andThymus vulgaris (Lamiaceae)

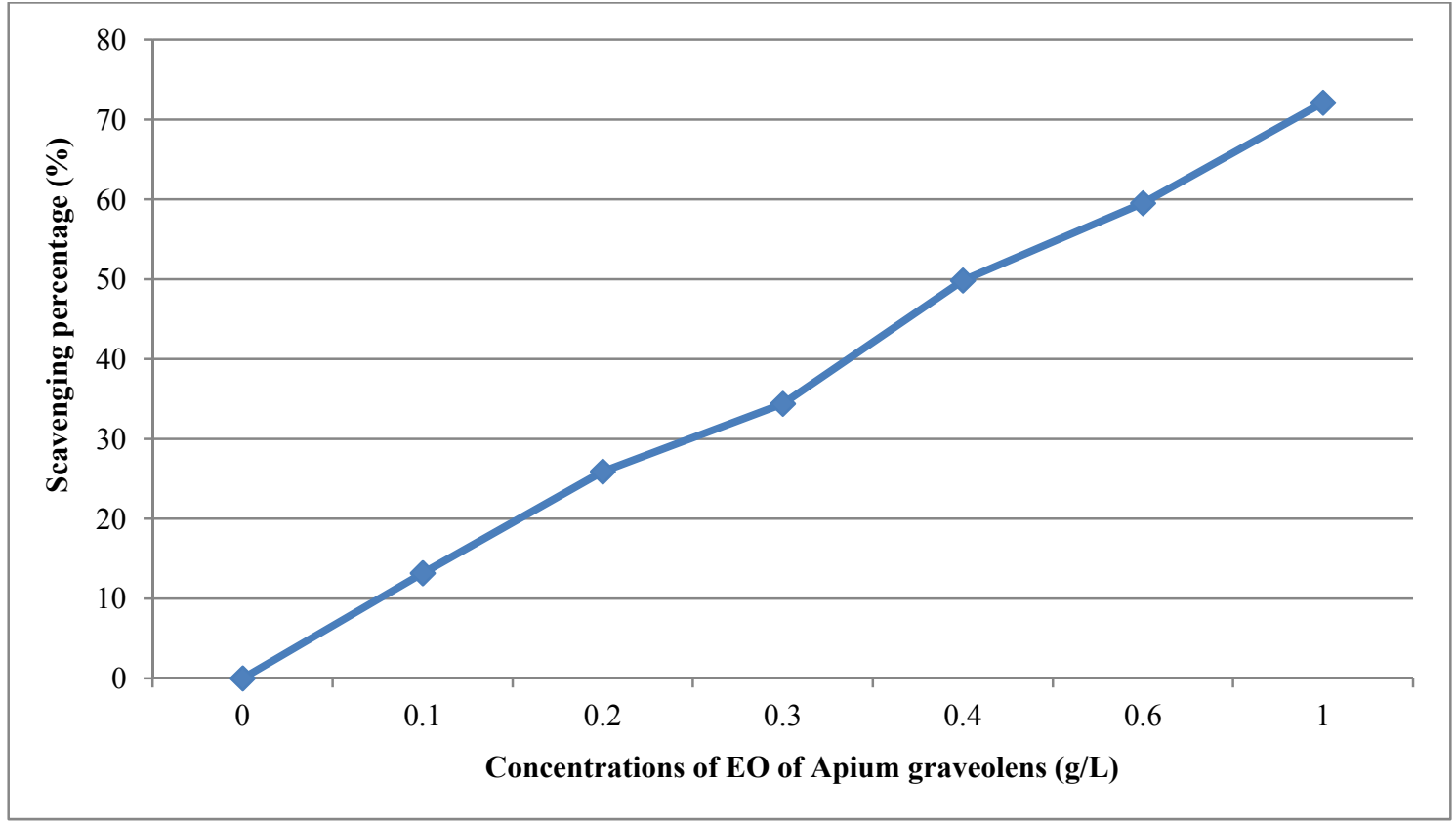

Fig. 2 Antiradical activity of essential oil of $A$. graveolens.

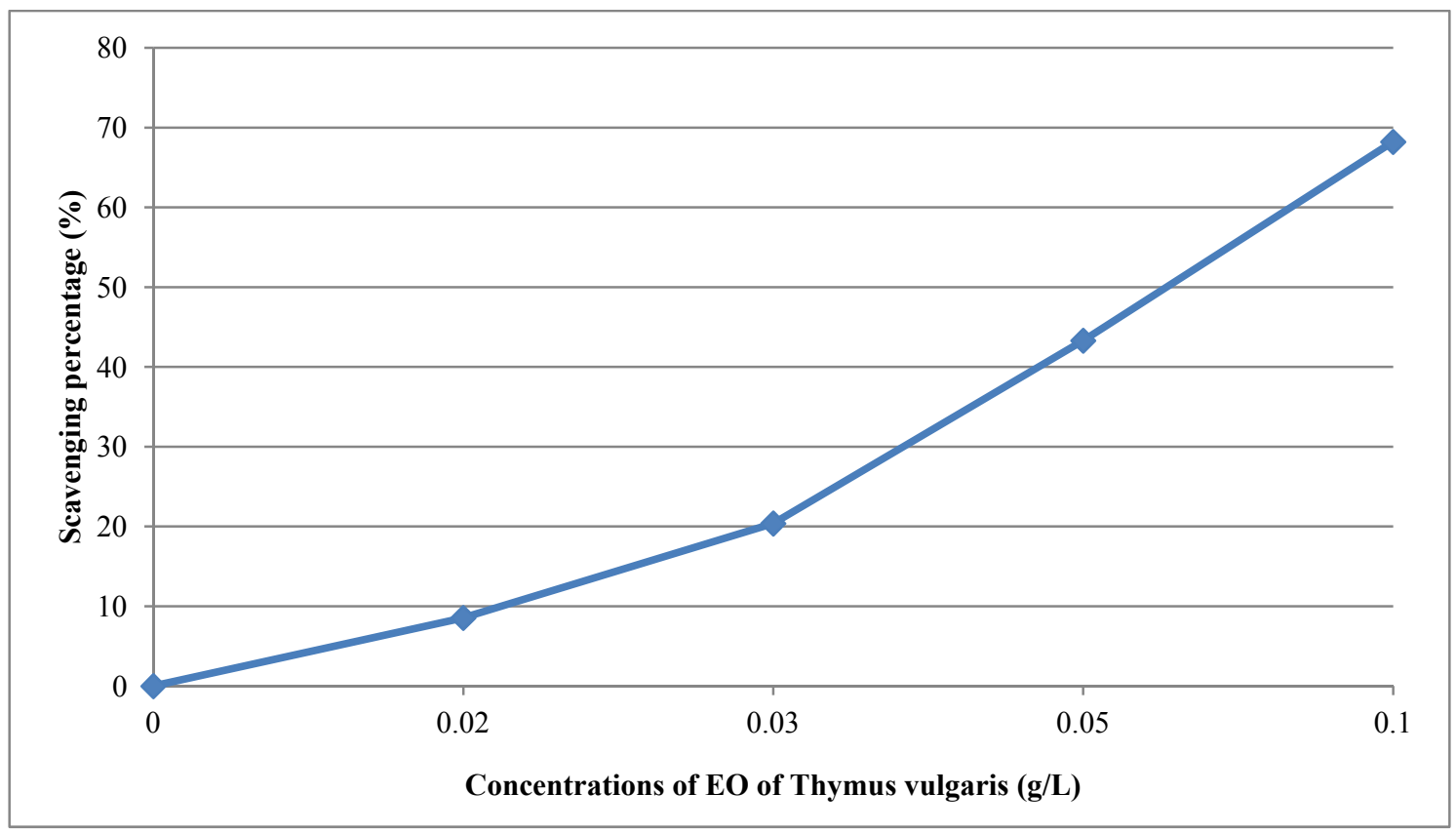

Fig. 3 Antiradical activity of essential oil of T. vulgaris.

Table $3 \mathrm{SC}_{50}$ (scavenging concentration 50), $\mathbf{E C}_{50}$ (effective concentration 50) and $\mathrm{AC}$ (antiradical capacity) values of the studied samples and BHT.

\begin{tabular}{llll}
\hline Samples & $\mathrm{SC}_{50}(\mathrm{~g} / \mathrm{L})$ & $\begin{array}{l}\mathrm{EC}_{50} \\
\mathrm{~g} / \mathrm{mol} \mathrm{de} \mathrm{DPPH}\end{array}$ & $\mathrm{AC}\left(\mathrm{x} \mathrm{10} 0^{-3}\right) \mathrm{mol}$ \\
\hline BHT & $0.007 \pm 0.000^{\mathrm{a}}$ & $7.35 \pm 0.000^{\mathrm{a}}$ & $136.13 \pm 11.71^{\mathrm{a}}$ \\
A. graveolens & $0.41 \pm 0.01^{\mathrm{b}}$ & $482.75 \pm 0.02^{\mathrm{b}}$ & $2.07 \pm 0.67^{\mathrm{b}}$ \\
T. vulgaris & $0.06 \pm 0.01^{\mathrm{c}}$ & $62.97 \pm 0.01^{\mathrm{c}}$ & $15.88 \pm 5.37^{\mathrm{c}}$ \\
\hline
\end{tabular}

$\mathrm{a}, \mathrm{b}$ indicate the statistical analysis, in the same column the activity of three compounds is different $(P \leq 0.05)$. 
Antiradical, Anti-inflammatory and Antifungal Activities of Essential Oils of Two Aromatic Plants: Apium graveolens (Apiaceae) andThymus vulgaris (Lamiaceae)

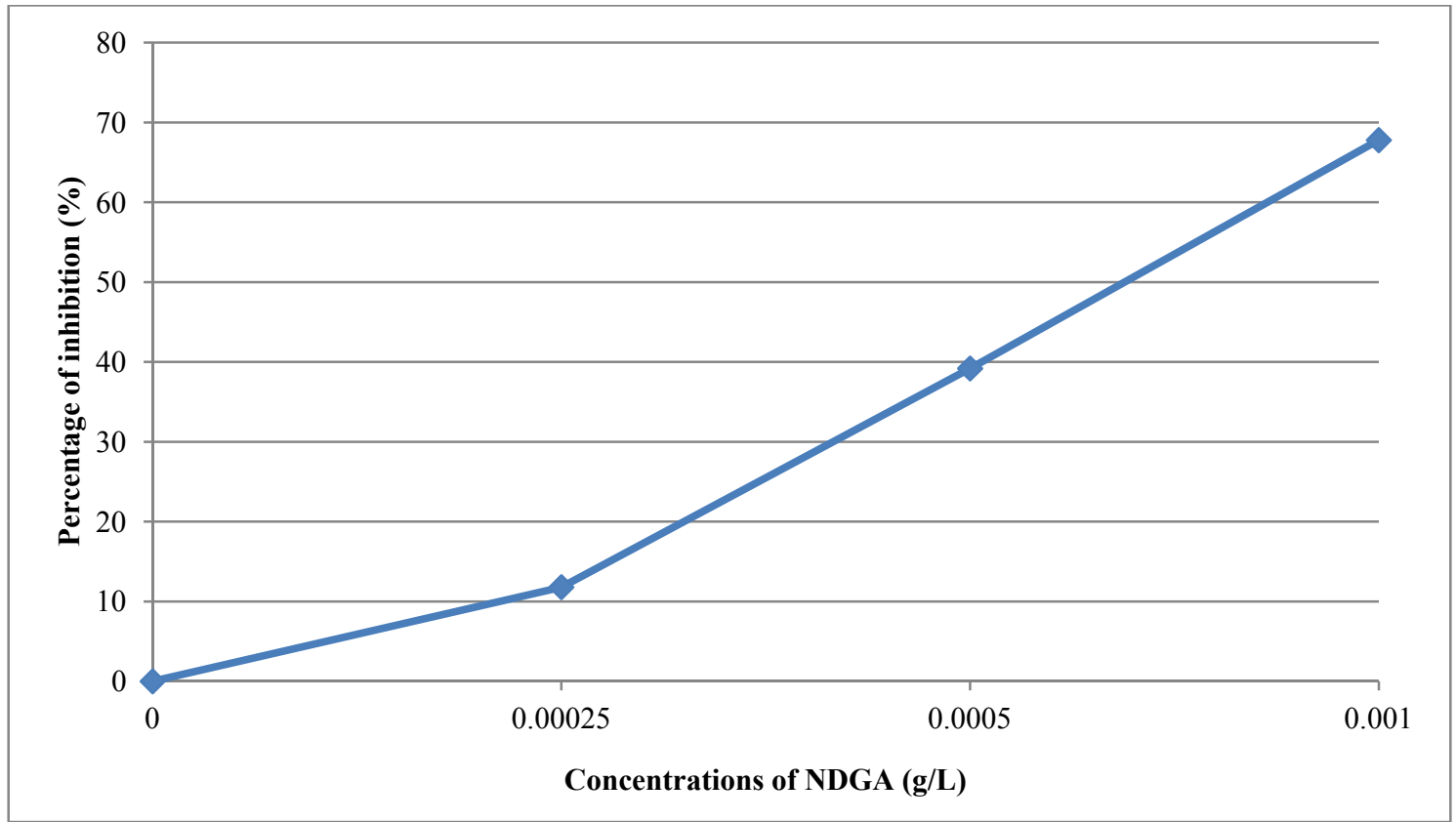

Fig. 4 Anti-inflammatory activity of NDGA.

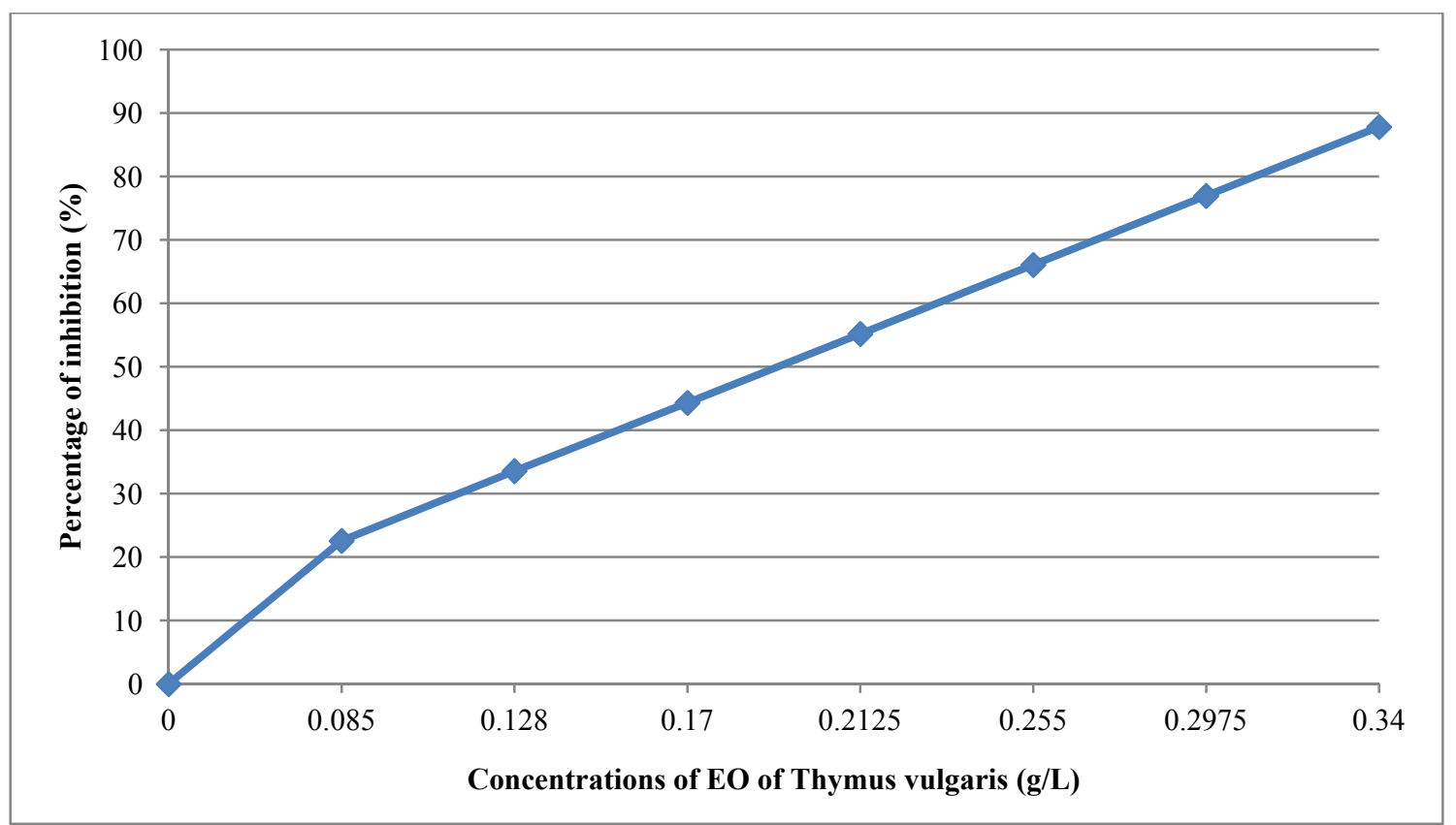

Fig. 5 Anti-inflammatory activity of essential oil of $T$. vulgaris.

Table $4 \mathrm{IC}_{50}$ values of the studied samples.

\begin{tabular}{ll}
\hline Samle & $\mathrm{IC}_{50}(\mathrm{~g} / \mathrm{L})$ \\
\hline ANDG & $0.0007 \pm 0.000^{\mathrm{a}}$ \\
A. graveolens & - \\
T. vulgaris & $0.192 \pm 0.011^{\mathrm{b}}$ \\
\hline
\end{tabular}

$\mathrm{a}, \mathrm{b}$ indicate the statistical analysis, in the same column the activity of two compounds is different $(P \leq 0.05)$. 
and the sample of Thymus vulgaris is less active than NDGA.

\subsection{Antifungal Activity}

\subsubsection{Anti-Yeast Activities}

The results of the disc diffusion testing of essential oils are listed in Tables 5 and 6.

The Table 6 shows that the inhibition zone diameter of the essential oils tested varies from 0 to $13.87 \mathrm{~mm}$. The strongest activity was shown against $C$. albicans with 13.0 and $13.87 \mathrm{~mm}$ inhibition zone. The NC (negative controls) showed no inhibiting effect. All isolates were found sensitive to Nystatin (positive control).

The results in Table 7 indicate that their MIC varied, respectively, from 8.87 to $70 \mathrm{~g} / \mathrm{L}$ for essential oil of $A$. graveolens and from 0.22 to $0.89 \mathrm{~g} / \mathrm{L}$ for essential oil of $T$. vulgaris. C. albicans was shown to be resistant at the highest concentration tested $(70 \mathrm{~g} / \mathrm{L})$ for essential oil of $A$. graveolens and $C$. glabrata for essential oil of $T$. vulgaris at $0.89 \mathrm{~g} / \mathrm{L}$. These essential oils were fungicidal at the same concentrations.

\subsubsection{Anti-Mould Activities}

The Figs. 6 and 7 show that for two essential oils at the three concentrations tested, the inhibition varies from 0 to $100 \%$. At $0.255 \mathrm{~g} / \mathrm{L}$, no inhibitions on $A$. fumigatus was observed with the $T$. vulgaris essential oil. Whereas at 0.51 and $5.1 \mathrm{~g} / \mathrm{L}, 100 \%$ of inhibition was observed on A. flavus and A. fumigatus.

Table 5 Diameter of inhibition zone (mm) from essential oil of $\boldsymbol{A}$. graveolens.

\begin{tabular}{llll}
\hline Conc AG $(\mathrm{g} / \mathrm{L})$ & C. albicans & C. glabrata & Cr. neoformans \\
\hline Nyst & $15.62 \pm 0.17$ & $7.75 \pm 0.70$ & $13.50 \pm 0.70$ \\
170 & $0.00 \pm 0.00$ & $0.00 \pm 0.00$ & $0.00 \pm 0.00$ \\
250 & $6.87 \pm 1.23$ & $5.25 \pm 1.76$ & $7.75 \pm 0.35$ \\
340 & $8.62 \pm 0.88$ & $7.37 \pm 0.53$ & $8.62 \pm 0.88$ \\
420 & $13.87 \pm 0.53$ & $7.50 \pm 0.70$ & $10.62 \pm 1.23$ \\
DMSO & $0.00 \pm 0.00$ & $0.00 \pm 0.00$ & $0.00 \pm 0.00$ \\
NC & $0.00 \pm 0.00$ & $0.00 \pm 0.00$ & $0.00 \pm 0.00$
\end{tabular}

AG: A. graveolens; Nyst: Nystatin; NC: Negative control.

Table 6 Diameter of inhibition zone (mm) from essential oil of $T$. vulgaris.

\begin{tabular}{llll}
\hline Conc TV $(\mathrm{g} / \mathrm{L})$ & C. albicans & C. glabrata & Cr. neoformans \\
\hline Nyst & $15.62 \pm 0.17$ & $7.75 \pm 0.70$ & $13.50 \pm 0.70$ \\
42.50 & $4.25 \pm 1.06$ & $0.00 \pm 0.00$ & $0.00 \pm 0.00$ \\
85.00 & $6.62 \pm 2.29$ & $3.75 \pm 0.35$ & $6.00 \pm 1.41$ \\
212.50 & $8.25 \pm 1.6$ & $4.50 \pm 0.0$ & $7.50 \pm 0.70$ \\
255.00 & $13.00 \pm 1.41$ & $7.50 \pm 2.12$ & $9.00 \pm 1.41$ \\
DMSO & $0.00 \pm 0.00$ & $0.00 \pm 0.00$ & $0.00 \pm 0.00$ \\
NC & $0.00 \pm 0.00$ & $0.00 \pm 0.00$ & $0.00 \pm 0.00$ \\
\hline
\end{tabular}

AG: A. graveolens; Nyst: Nystatine; NC: Negative control.

Table 7 MIC and MFC of essential oils.

\begin{tabular}{|c|c|c|c|c|c|c|}
\hline \multirow{2}{*}{ Parameter } & \multicolumn{2}{|c|}{ C. albicans } & \multicolumn{2}{|c|}{ C. glabrata } & \multicolumn{2}{|c|}{ Cr. neoformans } \\
\hline & $\overline{A G}$ & TV & $\overline{A G}$ & TV & $\overline{A G}$ & TV \\
\hline MIC (g/L) & 70.00 & 0.55 & 17.50 & 0.44 & 4.37 & 0.11 \\
\hline MFC (g/L) & 70.00 & 0.55 & 35.00 & 0.89 & 8.75 & 0.22 \\
\hline MFC/MIC & 1.00 & 1.00 & 2.00 & 2.00 & 2.00 & 2.00 \\
\hline
\end{tabular}

AG: A. Graveolens; TV: T. Vulgaris. 

Apium graveolens (Apiaceae) andThymus vulgaris (Lamiaceae)

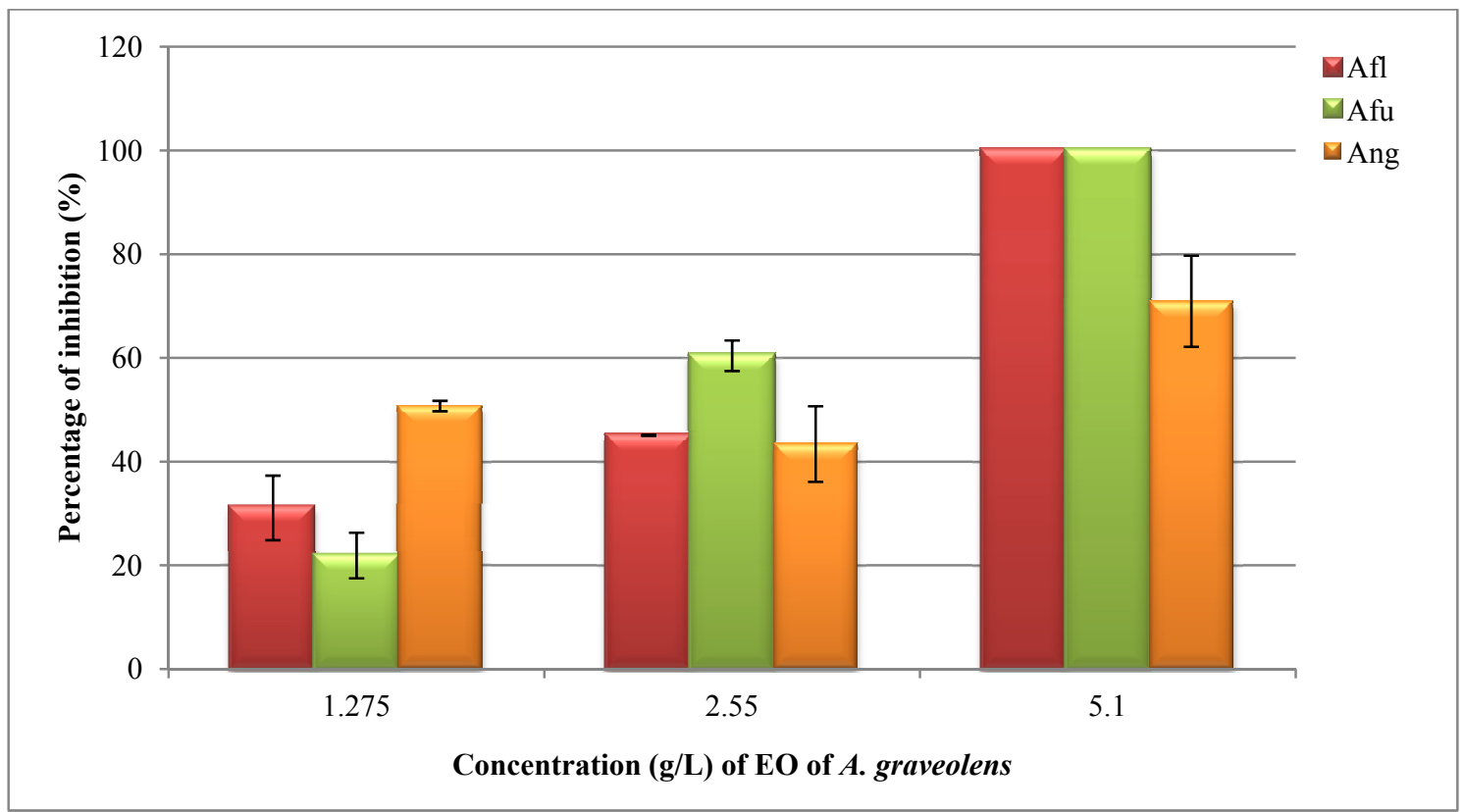

Fig. 6 Percentage of inhibition of essential oil of $A$. graveolens.

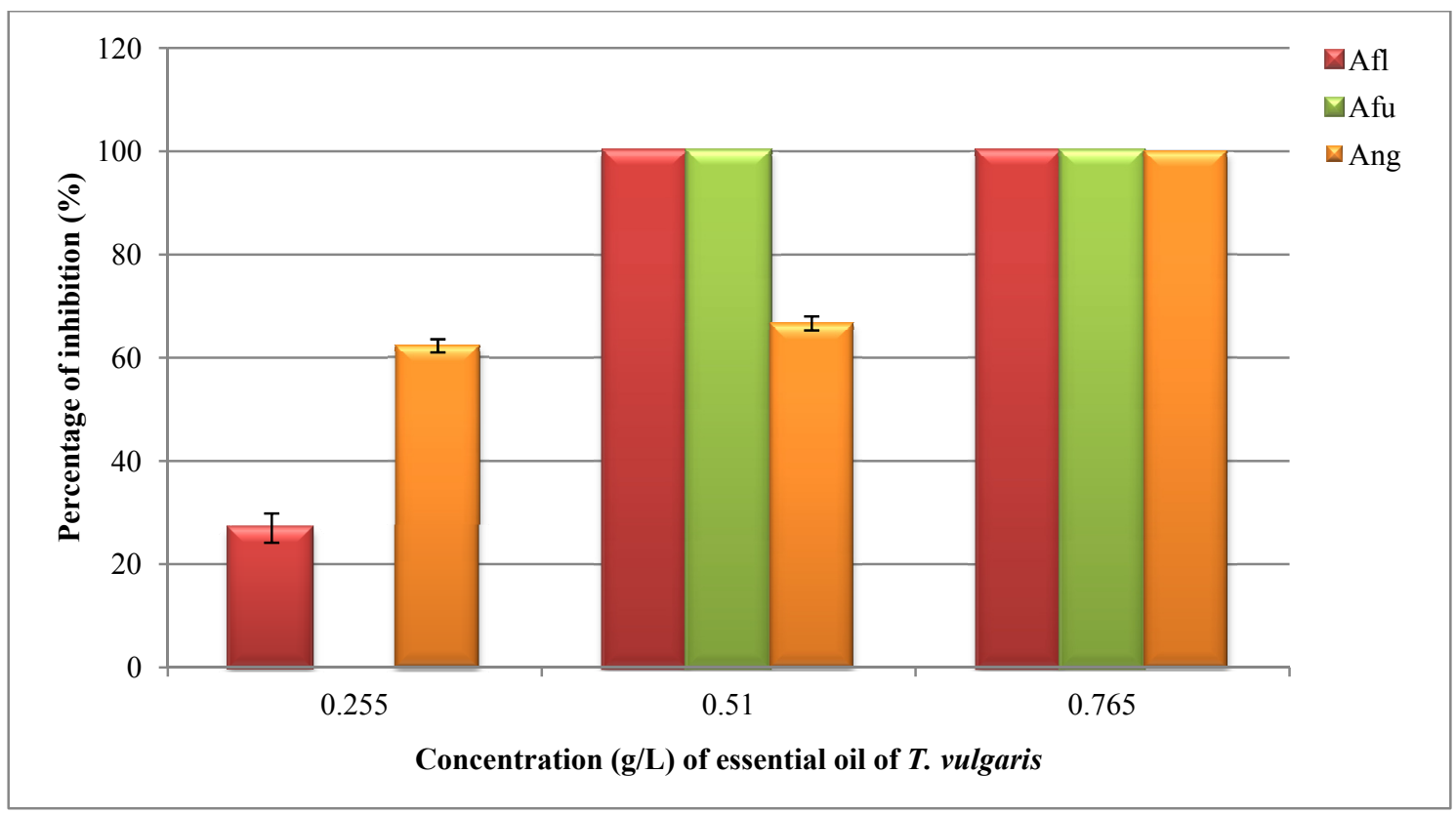

Fig. 7 Percentage of inhibition of essential oil of $T$. vulgaris.

Afl: Apergillusflavus; Afu: Apergillusfumigatus; Ang: Apergillusniger.

The results of MIC on moulds are presented in Table 8 . The value varies between 4.68 to $6.80 \mathrm{~g} / \mathrm{L}$ for essential oil of $A$. graveolens and 0.47 to $0.55 \mathrm{~g} / \mathrm{L}$ for essential oil of $T$. vulgaris. The essential oil of $T$. vulgaris showed the best activity than A. graveolens. The strongest activity was shown against $A$. fumigatus with 0.47 and $4.68 \mathrm{~g} / \mathrm{L}$ MIC values. They also showed moderate activities against $A$. niger with 0.55 and 6.80 $\mathrm{g} / \mathrm{L}$ MIC values for essential oils of $T$. vulgaris and $A$. graveolens respectively. All isolates were found sensitive to Amphotericin B (positive control).

\subsubsection{Anti-dermatophyte Activities}

The Figs 8 and 9 show that the percentage inhibition of dermatophytes varies from 16 to $100 \%$. 
Table 8 MIC and MFC of essential oils.

\begin{tabular}{|c|c|c|c|c|c|c|}
\hline \multirow{2}{*}{ Parameter } & \multicolumn{2}{|c|}{ A. flavus } & \multicolumn{2}{|c|}{ A. fumigatus } & \multicolumn{2}{|c|}{ A. niger } \\
\hline & $\overline{\mathrm{AG}}$ & $\mathrm{TV}$ & $\mathrm{AG}$ & $\mathrm{TV}$ & $\mathrm{AG}$ & TV \\
\hline MIC (g/L) & 4.68 & 0.49 & 4.68 & 0.47 & 6.80 & 0.55 \\
\hline $\mathrm{MFC}(\mathrm{g} / \mathrm{L})$ & 5.10 & 0.49 & 5.10 & 0.47 & 6.80 & 0.55 \\
\hline MFC/MIC & 1.09 & 1.00 & 1.09 & 1.00 & 1.00 & 1.00 \\
\hline
\end{tabular}

AG: A. Graveolens; TV: T. vulgaris.

At $0.255 \mathrm{~g} / \mathrm{L}$ and $2.55 \mathrm{~g} / \mathrm{L}, 100 \%$ of inhibitions on $T$. mentagrophytes was observed with the $T$. vulgaris essential oil whereas the $A$. graveolens essential oil at 0.51 and $5.1 \mathrm{~g} / \mathrm{L} 100 \%$ of inhibitions on the three species.

The MIC of dermatophytes is presented in Table 9. It varies between 1.28 to $3.40 \mathrm{~g} / \mathrm{L}$ for essential oil of $A$. graveolens and 0.26 to $0.43 \mathrm{~g} / \mathrm{L}$ for $T$. vulgaris essential oil. The essential oil of $T$. vulgaris showed the best activity against $T$. mentagrophytes at $0.26 \mathrm{~g} / \mathrm{L}$ than that of $A$. graveolens. It also showed moderate activities against $E$. flocosum with 0.43 and $3.40 \mathrm{~g} / \mathrm{L}$ for essential oils of $T$. vulgaris and A. graveolens respectively. All isolates were found sensitive to Amphotericin B and Griseofulvin.

The essential oil of $A$. graveolens is rich in limonene (50.7\%) and myrcene (12.5\%) whereas thymol $(57.9 \%)$ and p-cymene $(10.3 \%)$ were present in that of $T$. vulgaris. This composition is similar to previous reports by Alfreda and Taka [18] and Nguefack et al. [17]. The presence of thymol in these essential oils is among a group of chemicals known as monoterpenes which are the strongest activity against fungus [22]. All the concentrations of the essential oils inhibited the fungal species with varying degree of sensitivity. The yeast species were more resistant than the moulds. C. neoformans was the most susceptible yeast strain and $C$. albicans was more resistant. The most susceptible mould strain was $A$. fumigatus and the more resistant was $A$. niger. The $T$. vulgaris oil showed best antifungal activity than $A$. graveolens oil. E. flocosum was more resistant than other dermatophytes and these results corroborate for those of Ouraïni et al. [23] who studied of fungitoxic

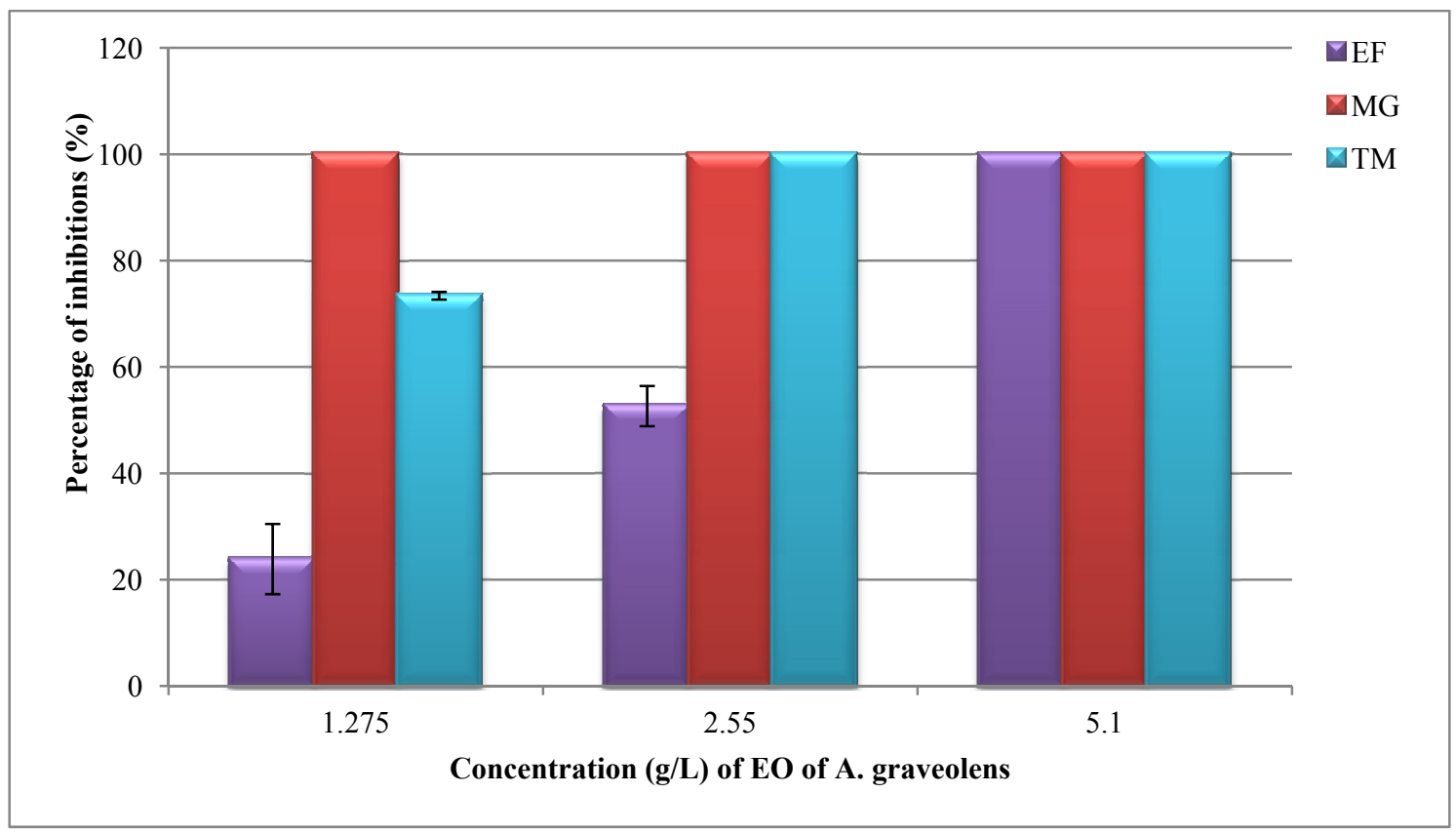

Fig. 8 Percentage of inhibition of essential oil of A. graveolens. 

Apium graveolens (Apiaceae) andThymus vulgaris (Lamiaceae)

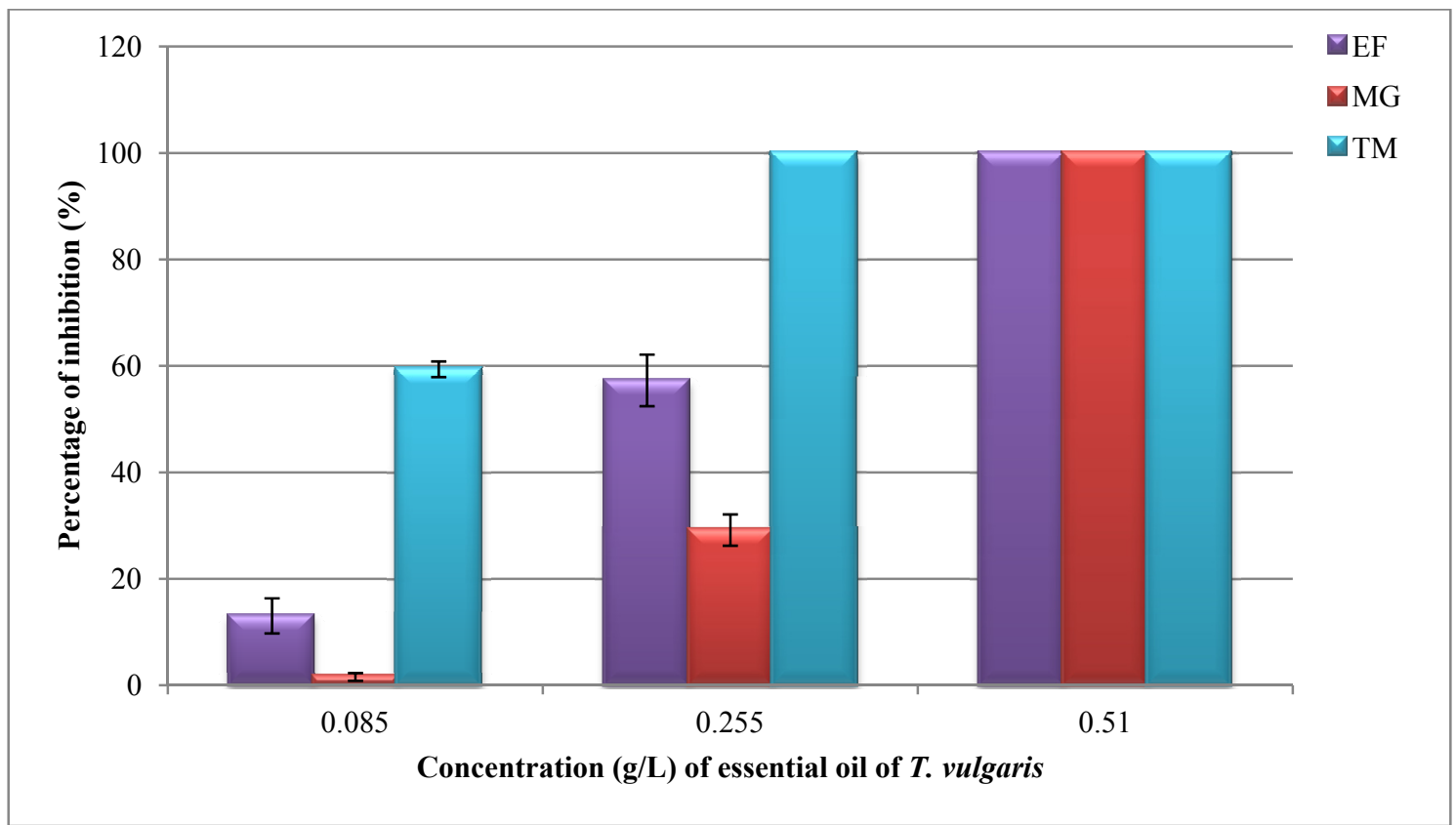

Fig. 9 Percentage of inhibition of essential oil of $T$. vulgaris.

EF: Epidermophytonflocosum; MG: Microsporumgypseum; TM: Trichophytonmentagrophytes.

Table 9 MIC and MFC of essential oils.

\begin{tabular}{|c|c|c|c|c|c|c|}
\hline \multirow{2}{*}{ Parameter } & \multicolumn{2}{|c|}{ E. flocosum } & \multicolumn{2}{|c|}{ M. gypseum } & \multicolumn{2}{|c|}{ T. mentagrophytes } \\
\hline & $\mathrm{AG}$ & TV & $\mathrm{AG}$ & TV & $\mathrm{AG}$ & TV \\
\hline MIC (g/L) & 3.40 & 0.43 & 1.28 & 0.43 & 2.13 & 0.26 \\
\hline MFC (g/L) & 3.40 & 0.51 & 1.28 & 0.51 & 2.55 & 0.43 \\
\hline MFC/MIC & 1.00 & 1.20 & 1.00 & $` 1.20$ & 1.20 & 1.65 \\
\hline
\end{tabular}

AG: A. Graveolens; TV: T. vulgaris.

activity of essential oils of aromatic and medicinal plants such as thyme (Thymus saturejoides L.), European pennyroyal (Menthe pulegium L.) and rosemary (Rosmarinus officinalis L.) on the germination, mycelial growth and sporulation of dermatophytes responsible for different cases of mycoses among humans. These two plants have been previously observed to possess antifungal activity [24]. The presence of biologically active compounds (thymol, carvacrol) in the essential oils could be correlated to its antifungal activity. In fact, the poor antifungal activity of $A$. graveolens oil could be due to lowest quantity of thymol than limonene which may not play the major role in the antifungal activity [7]. The best activity of $T$. vulgaris oil could be due to the thymol which is responsible for the highest antifungal activity among terpenoids $[25,26]$.

\section{Conclusion}

The essential oils of $A$. graveolens and T. vulgaris constitute a source of natural antioxidants, anti-infammatory and antifungal. They are therefore beneficial for traditional medicine in the prevention and cure of some diseases. In addition, these plants could be used as food supplements in the protection against some emergent diseases.

\section{References}

[1] Monique, G., Dominique, B., Zohreh, A., and Daniel, J. 2003. "Espèces réactives de l'oxygène. Comment l'oxygène peut-il devenir toxique?" L'actualité chimique 91-6.

[2] Cesaroni, I., Negro, F., and Guerrini, M. 2007. 


\section{Apium graveolens (Apiaceae) andThymus vulgaris (Lamiaceae)}

"Malnutrition, Stress and Immunodepression: The Inter Relationship with Fungal Infections." In Proceedings of the Nutrition Society, 67-10.

[3] Penelope, O. 1994. Les plantes médicinales, Encyclopédie Pratique. Paris: Reader's Digest.

[4] Alexander, M. 2001. "Aromatherapy and Immunity: How the Use of Essential Oil in Aids Immune Potentiality. Part 3: Immune Response to Inflammation and Essential Oils Useful in Inhibiting Them." International Journal of Aromatherapy 11 (4): 220-4.

[5] Baylac, S., and Racine, P. 2003. "Inhibition of 5-lipoxygenase by Essential Oil and Other Natural Fragrant Extract." International Journal of Aromatherapy 13 (2): 138-42.

[6] Bhusita, W., Siripen, J., Thammathad, S., and Sirinun T. 2005. "Antibacterial Properties of Essential Oils from Thai Medicinal Plants." Fitoterapia 76: 233-6.

[7] Jazet, D. P. M., Kuate, J., Ngouana, V., Damesse, F., Tchinda, S. E., and Amvam, Z. P. H. 2008. "Analyse comparative des propriétés antiradicalaires et Anti-infammatoires des Huiles Essentielles de Citrus reticulata var. Madagascar et Citrus sinensis var. casagrande du Cameroun." Fruits 63 (4): 201-8.

[8] Adams, R. P. 2007. Identification of Essential Oils by Gas Chromatography/Quadrupole Mass Spectroscopy. Carol Stream: Allured Publishing Corporation.

[9] Brand-Williams, W., Cuvelier, M. E., and Berset, C. 1995. "Use of Free Radical Method to Evaluate Antioxydant Activity, LWT-Food." Science and Technology 28: 25-30.

[10] Cuvelier, M. E., Richard, H., and Berset, C. 1997. "Comparison of the Antioxidative Activity of Some Acid Phenols: Structure-Activity Relationship." Bioscience Biotechnology Biochemistry 56: 324-5.

[11] Safayhi, H., Mack, T., Sabiaera, J. J., Anazodo, M. I., Subramanian, L. R., and Ammon, H. P. T. 1992. "Bosswelic Acids: Novel, Specific, Non Redox Inhibitiors of 5-lipoxygenase." Journal of Pharmacology 26 (3): 1143-6.

[12] Braga, F., Wagner, H., Lombardi, J. A., and Braga, D. 2000. "Screening Brazilian Plant Species for in vitro Inhibition of 5-lipoxygenase." Phytomedicine 6 (6): 447-52.

[13] Rubio, M. C., Gil I. R., De Ocariz, J., Benito, R., and Rezusta, A. 2003. "Comparison of Results Obtained by Testing with Three Deferent Agar Media and by the NCCLS M27-A Method for in vitro Testing of Fluconazole Against Candida spp." Journal of Clinical Microbiology 41: 2665-8.

[14] Tchoumbougnang, F. 1997. "Contribution à la détermination des teneurs, des caractéristiques chimiques et des activités antifongiques des huiles essentielles de quelques plantes aromatiques, condimentaires et médicinales du Cameroun.” Thèse de Doctorat $3^{\text {eme }}$ cycle en Biochimie, Université de Yaoundé I.

[15] De Billerbeck, G. 2000. “Activité fongique de l'huile essentielle de Cymbopogon nardus sur Aspergillus niger. Evaluation d'un bioréacteur pour l'étude de l'effet inhibiteur des substances volatiles en phase vapeur." Faculté des Sciences Pharmaceutiques, Institut National Polytechnique de Toulouse.

[16] Grover, R. K., and Moore, J. D. 1962. "Toximetric Studies of Fungicides Against Brown Rot Organism: $S$. fructicola et S. laxa." Phytopathoogy 52: 876-80.

[17] Nguefack, J., Nguikwi, K. S., Fotio, D., Dongmo, B., and Zollo, A. P. H. 2007. "Fungicidal Potential of Essential Oils and Fractions from Cympobogon citratus, Ocimum gratissimum and Thymus vulgaris to Control Alternaria padwickii and Bipolaris oryzae, Two Seed Borne Fungi of Rice (Oryza sativa L.)." Journal of Essential Oil Research 19: 581-7.

[18] Alfreda, W., and Taka, Y. 2007. "Antioxidant Activities and Volatiles Constituents of Various Essentials Oils." Journal of Agricultural and Food Chemistry 55 (5): 1737-42.

[19] Alitonou, G. A. 2006. "Huiles Essentielles Extraites de Plantes Aromatiques d'origine Beninoise: Etude Chimique, Evaluation Biologique et Applications Potentielles.” Ph.D. thesis, Universités de Montpellier II et d' Abomey Calavi du Bénin.

[20] Yakhlef, 2010. "Etude de l'activité Biologique des Extraits de Feuilles de Thymus vulgaris L. et Laurus nobilis L. " Master's thesis, Université El Hadj Lakhdar.

[21] Sokmen, A., Gulluce, M., and Akpulat, A. 2005. "The in vitro Antimicrobial and Antioxidant Activities of the Essential Oils and Methanol Extracts of Endemic Thymus spathulifolius." Food Control 15 (8): 627-34.

[22] Karmen, V., Bojana, B., Vrtacnik, M., and Pohleven, F. 2003. "Effect of the Antifungal Activity of Oxygenated Aromatic Essential Oil Compounds on the White-Rot Trametes versicolor and the Brown-rot Coniophora puteana, Int. Biodeterior." Biodegradation 51: 51-59.

[23] Ouraïni, D., Agoumi, A., Ismaili-Alaoui, M., Alaoui, K., Cherrah, Y., Amrani, M., and Belabbas, M., 2005. "Etude de l'activité des Huiles Essentielles de Plantes Aromatiques à Propriétés Antifongiques sur les Différentes Etapes du Développement des Dermatophytes." Phytothérapie 3 (4): 147-57.

[24] Nguefack, J., Lekagne, D. J. B., Dakole, C. D., Leth, B. V., Vismer, H. F., Torp, J., Guemdjom, E. F. N., Mbeffo, M., Tamgue, O., Fotio, D., Amvam, Z. P. H., and 

Apium graveolens (Apiaceae) andThymus vulgaris (Lamiaceae)

Nkengfack, A. E. 2009. "Food Preservative Potential of Essential Oils and Fractions from Cymbopogon citratus, Ocimum gratissimum and Thymus vulgaris Against Mycotoxigenic Fungi.” International Journal of Food Microbiology 131: 151-6.

[25] Chebli, B., Achouri, M., Idrissi Hassani, L. M., and Hmamouchi, M. 2003. "Chemical Composition and
Antifungal Activity of Essential Oils of Seven Moroccan Labiatae Against Botrytis cinerea." Journal of Ethnopharmacology 89: 165-9.

[26] Hammer, K. A., Carson, C. E., and Riley, T. V. 2003. "Antifungal Activity of the Components of Melaleuca alternifolia (tea tree) Oil." Journal of Applied Microbiology 95: 853-60. 